\title{
Ce/Mo metal oxides synthesized with DBD plasma as efficient photocatalysts: Effect of Ce/Mo molar ratios
}

\author{
Kangkang Zheng ${ }^{1}$, and Xumei Tao ${ }^{1 *}$ \\ ${ }^{1}$ State Key Laboratory Base for Eco-Chemical Engineering, College of Chemical Engineering, \\ Qingdao University of Science and Technology, Qingdao 266042 Shandong, China
}

\begin{abstract}
Ce} / \mathrm{Mo}$ metal oxides with different $\mathrm{Ce} / \mathrm{Mo}$ molar ratios were synthesized via dielectric barrier discharge (DBD) method for the first time and applied as efficient photocatalysts. The morphology and physicochemical properties of the synthesized samples were characterized by XRD, SEM, BET and XPS. $\mathrm{Ce} / \mathrm{Mo}$ metal oxides synthesized with $\mathrm{Ce}\left(\mathrm{NO}_{3}\right)_{3} \cdot 6 \mathrm{H}_{2} \mathrm{O}$ and $\left(\mathrm{NH}_{4}\right)_{6} \mathrm{Mo}_{7} \mathrm{O}_{24} \cdot 4 \mathrm{H}_{2} \mathrm{O}$ molar ratio of $4: 1$ exhibited more surface chemical adsorption of oxygen, which were beneficial to the photocatalytic performance. The degradation rate of $1000 \mathrm{~mL}(50 \mathrm{mg} / \mathrm{L})$ methyl orange could reach $80 \%$ within $18 \mathrm{~min}$ under UV-light radiation. Ce/Mo metal oxides exhibited excellent photocatalytic performance and had potential application prospect in dye wastewater treatment.
\end{abstract}

\section{INTRODUCTION}

Environmental problems become more and more serious nowadays. Photocatalytic technology plays an important role in environmental governance [1]. Photocatalytic technology is a process of redox reaction on the surface of catalyst under the action of light energy [2,3]. This method not only saves cost, but also has less environmental pollution. Photocatalyst is not only the premise of photocatalytic reaction, but also the core of photocatalytic oxidation [4]. Therefore, the development and selection of photocatalyst with high efficiency and good performance is the key step of photocatalytic reaction $[5,6]$.

With the development of photocatalytic materials, the variety of photocatalyst is enriched. The selection of higher efficient photocatalyst is important to the photocatalytic reaction [4]. Ce/Mo metal oxides have been widely studied as redox catalysts in the field of catalysis [7,8]. Yang et al [9] successfully synthesized three-dimensional (3D) flower-like Ce-Mo micro/nano composite oxides $\left(f-\mathrm{Ce}_{10-x} \mathrm{Mo}_{x} \mathrm{O}_{\delta}\right)$ with different $\mathrm{Ce}-\mathrm{Mo}$ atomic ratios as effective bifunctional catalysts for onepot conversion of fructose to 2,5-diformylfuran (DFF). Dargahi et al [10] successfully prepared $\mathrm{Ce}_{2}\left(\mathrm{MoO}_{4}\right)_{3}$ nanoparticles via microemulsion, which showed excellent photodegradation. Molybdenum ions could change the valence site of Ce, creating defect structures and providing active sites for reactant molecules. Defect structures can be produced in the conversion process of high valence states $\mathrm{Ce}^{4+}$ to low valence states $\mathrm{Ce}^{3+}$, which can give new materials good light response ability.

With the popularization of advanced technology, innovative methods of catalyst preparation have been developed. In recent years, plasma technology has been paid great attention to the synthesis of nanoparticles and the modification of catalyst surface, which has very important practical value [11]. Plasma is a kind of ionized gas, which is composed of various types of positive and negative ions, and a large number of neutral substances, such as atoms, molecules, electrons, free radicals and neutral particles of stimulated species $[12,13]$. These particles can be used as active components for catalyst preparation and processing [14]. The plasma method can produce nano-materials with relatively regular crystal grains under appropriate conditions [15]. In addition, this technology can ensure that the reaction system has a lower temperature, at the same time, it can provide enough energy to activate the reactant molecules and then initiate chemical reactions $[16,17]$. Yang et al [18] prepared $\mathrm{ZnCuFeCr-LHDs} \mathrm{with}$ DBD plasma, which showed controlled particle size and good catalytic performance. Besides, compared with different preparation methods, $\mathrm{ZnCuFeCr-LHDs}$ prepared via DBD plasma can rapidly and effectively promote the formation and growth of crystal nucleus. Khaledian et al [19] prepared $\mathrm{LaMnO}_{3} / \mathrm{CeO}_{2}$ nano catalysts by dry impregnation method and modified by plasma technology, which improved the dispersion of perovskite nanoparticles. The size of $\mathrm{LaMnO}_{3} / \mathrm{CeO}_{2}$ nano catalysts was greatly reduced, which may lead to larger effective surface area. The catalytic performance of $\mathrm{LaMnO}_{3} / \mathrm{CeO}_{2}$ was improved by plasma surface modification. Compared with the traditional technology, the proposed surface modification method was relatively simple and economical. Ananth et al [20] synthesize $\mathrm{Ag}_{2} \mathrm{O}$ and $\mathrm{Ag}_{2} \mathrm{O} / \mathrm{RuO}_{2}$ nanocomposite materials with good crystallinity via DBD plasma. Characterization results showed superior redox properties at high temperature.

* Corresponding author: Xumei Tao. E-mail: taoxumei@qust.edu.cn 
In this work, Ce/Mo metal oxides with different molar ratios were prepared via DBD plasma induced liquid phase method, and applied as efficient photocatalysts.

\section{EXPERIMENTAL AND METHODS}

\subsection{Experimental materials}

$\left(\mathrm{NH}_{4}\right)_{6} \mathrm{Mo}_{7} \mathrm{O}_{24} \cdot 4 \mathrm{H}_{2} \mathrm{O}, \mathrm{AR} ; \mathrm{Ce}\left(\mathrm{NO}_{3}\right)_{3} \cdot 6 \mathrm{H}_{2} \mathrm{O}, \mathrm{AR}$; methyl orange, AR; CTAB, AR; Tert butyl alcohol, AR; Ammonium oxalate, AR; P-benzoquinone AR.

\subsection{Synthesis of Ce/Mo metal oxides}

Ce/Mo metal oxides were synthesized by DBD plasma method (Figure 1). A certain amount of $\mathrm{Ce}\left(\mathrm{NO}_{3}\right)_{3} \cdot 6 \mathrm{H}_{2} \mathrm{O}$ and $\left(\mathrm{NH}_{4}\right)_{6} \mathrm{Mo}_{7} \mathrm{O}_{24} \cdot 4 \mathrm{H}_{2} \mathrm{O}$ (molar ratio of $3: 1,4: 1$ and 5:1), CTAB, polyethylene glycol 1000 (PEG1000) (weight ratio between surfactant and metal salt of 1.4) were dissolved in the deionized water to form a solution with concentration of $12 \mathrm{~g} / \mathrm{L}$. Then, the solution was pumped into the reactor, which consisted of two coaxial quartz tubes. The solution flowed into the inner tube, after it filled the inner tube, it fell down on the outside of the inner tube to form a liquid film. A voltage generator (CTP-2000 K Nanjing Suman Electronics Co, Ltd) was used to generate DBD plasma. The voltage was measured as $3.64 \mathrm{kV}$ by oscilloscope (UTD2012CEX, UNIT, Co, Ltd). The aluminum foil on the outer surface of the reactor served as the high voltage electrode, while a metal rod, together with the liquid in the inner tube, served as the low voltage electrode. After discharging for $120 \mathrm{~min}$, the samples were washed several times with anhydrous ethanol, and then dried for $10 \mathrm{~h}$ at $120{ }^{\circ} \mathrm{C}$. The synthesized samples with Ce/Mo molar ratios of 3:1, 4:1 and 5:1 were recorded as MO-1, MO-2 and MO-3, respectively.

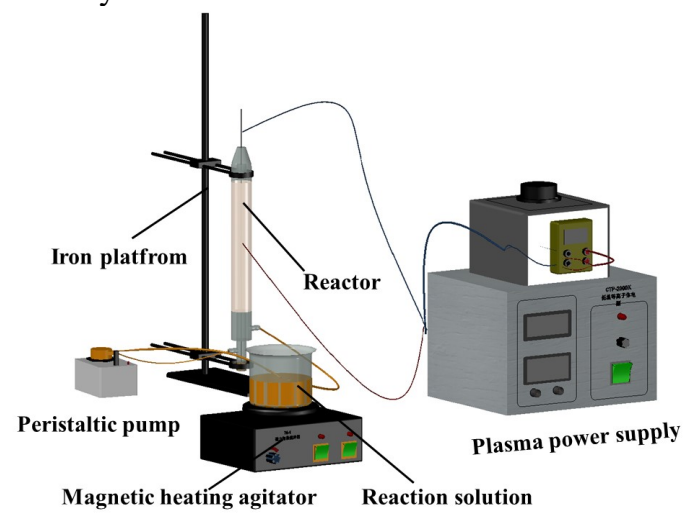

Figure 1 Diagram of reaction device for preparing $\mathrm{Ce} / \mathrm{Mo}$ metal oxides

\subsection{Photocatalytic experiments}

Photocatalytic degradation of MO was implemented with $0.8 \mathrm{~g} / \mathrm{L}$ photocatalysts suspended in $1000 \mathrm{~mL}(50 \mathrm{mg} / \mathrm{L})$ $\mathrm{MO}$ solution in the reactor with a hollow ring structure (Figure 2). $500 \mathrm{~W}$ ultraviolet lamp was inserted into the center of the cylindrical shell as the light source. MO solution and catalysts were stirred in the dark for 30 minutes. Then, they were pumped into the reactor and cycled. Meanwhile, the cooling water was circulated in the outside ring of the reactor. At regular intervals, $1 \mathrm{~mL}$ reaction solution was sampled, centrifugally separated and measured with ultraviolet visible spectrophotometer at $463 \mathrm{~nm}$.

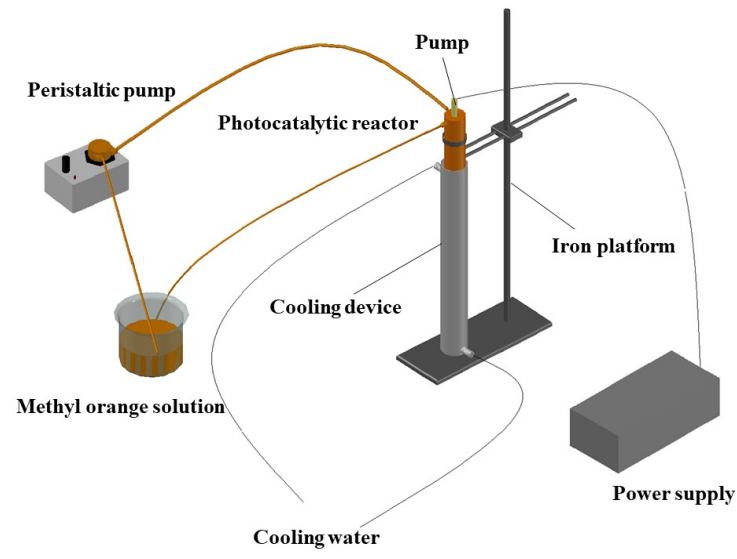

Figure 2 Experimental setup of photocatalytic reaction

The degradation rate of organic dye solution was defined as equation (1).

$$
\text { Degradation }=\left(1-C / C_{0}\right)=\left(1-A / A_{0}\right) \times 100 \%
$$

Where, $C_{0}$ and $C$ were the initial concentration and concentration at certain time; $A_{0}$ and $A$ were the initial absorbance and absorbance at certain time.

\section{RESULTS \& DISCUSSION}

\subsection{Characterization analysis of Ce/Mo metal oxides}

\subsection{1 $X R D$ results}

The XRD patterns of Ce/Mo metal oxides with different Ce/Mo molar ratios were shown in Figure 3.

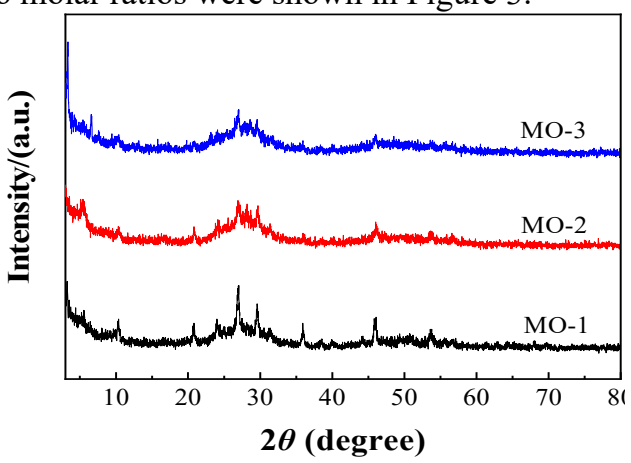

Figure 3 XRD patterns of Ce/Mo metal oxides with different $\mathrm{Ce} / \mathrm{Mo}$ molar ratios

The peaks at $2 \theta=38.51^{\circ}, 45.87^{\circ}$ and $56.75^{\circ}$ were indexed to $\mathrm{Ce}_{2}\left(\mathrm{MoO}_{4}\right)_{3}$ (PDF card 31-0331) [21,22], while the peaks at $2 \theta=24.01^{\circ}, 29.76^{\circ}, 31.57^{\circ}, 40.14^{\circ}$, $44.17^{\circ}$ and $49.57^{\circ}$ were related to $\beta-\mathrm{Ce}_{2} \mathrm{Mo}_{3} \mathrm{O}_{13}$ (PDF 
card 31-0332) [23]. Obviously, there were several forms of $\mathrm{Ce} / \mathrm{Mo}$ metal oxides in $\mathrm{Ce}_{2} \mathrm{Mo}_{3} \mathrm{O}_{x}$, which was due to the existence of various electronic satellite structures in the anions bound with $\mathrm{Ce}[24,25]$. With the increase of $\mathrm{Ce} / \mathrm{Mo}$ molar ratio, the crystallinity of $\mathrm{Ce}_{2} \mathrm{Mo}_{3} \mathrm{O}_{x}$ decreased gradually, which might be due to the high dispersion of $\mathrm{Ce}$ and Mo species.

\subsubsection{SEM results}

SEM images of Ce/Mo metal oxides with different Ce/Mo molar ratios were shown in Figure 4. It could be seen that the surface morphology of samples with different $\mathrm{Ce} / \mathrm{Mo}$ molar ratios were quite different. The MO-2 exhibited regular rod structure, while MO-1 and MO-3 did not show obvious regular structure, indicating that the appropriate Ce/Mo molar ratio was related to the formation of the structure of Ce/Mo metal oxides. The results verified that MO-2 was synthesized with regular rod structure, which could provide appropriate active sites for photocatalytic reaction.

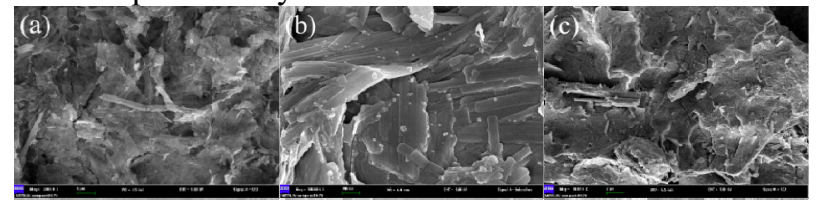

Figure 4 SEM images of Ce/Mo metal oxides with different $\mathrm{Ce} / \mathrm{Mo}$ molar ratios

(a) $\mathrm{MO}-1$; (b) $\mathrm{MO}-2$; (c) $\mathrm{MO}-3$

\subsubsection{BET results}

The $\mathrm{N}_{2}$ adsorption-desorption isotherms of Ce/Mo metal oxides with different $\mathrm{Ce} / \mathrm{Mo}$ molar ratios were shown in Figure 5. All Ce/Mo metal oxides showed typical typeIV sorption isotherms with type-H1 hysteresis loops, which confirmed the presence of micropore structure. The specific surface area of MO-1, MO-2 and MO-3 was $19.4 \mathrm{~m}^{2} / \mathrm{g}, 13.3 \mathrm{~m}^{2} / \mathrm{g}$ and $12.1 \mathrm{~m}^{2} / \mathrm{g}$, respectively. Larger surface area was beneficial to the adsorption of reactants.

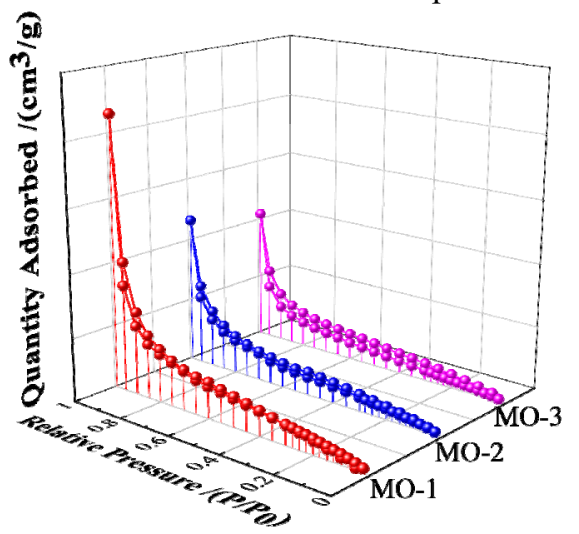

Figure $5 \mathrm{~N}_{2}$ adsorption desorption curves of Ce/Mo metal oxides with different $\mathrm{Ce} / \mathrm{Mo}$ molar ratios

\subsubsection{XPS results}

XPS spectrums of Ce/Mo metal oxides with different Ce/Mo molar ratios were shown in Figure 6. The peaks of $\mathrm{C}, \mathrm{Mo}, \mathrm{O}$, and $\mathrm{Ce}$ elements were clearly detected from XPS full spectrum, which verified the successful synthesis of $\mathrm{Ce} / \mathrm{Mo}$ metal oxides.

As shown in Figure 6 (b), the peaks could be assigned to $\mathrm{Ce} 3 \mathrm{~d}_{5 / 2}$ and $\mathrm{Ce} 3 \mathrm{~d}_{3 / 2}$ of $\mathrm{Ce} 3 \mathrm{~d}[7,9]$. Furthermore, the peaks marked with v' and u' symbols were ascribed to the presence of $\mathrm{Ce}^{3+}$, while the peaks with $\mathrm{v}, \mathrm{v}$ ", u, u' and u'" symbols were attribute to the presence of $\mathrm{Ce}^{4+}$, which indicated that there were mixed valence states of $\mathrm{Ce}$ ions in the $\mathrm{Ce} / \mathrm{Mo}$ metal oxides. Because of the cyclic transformation of the valence state between $\mathrm{Ce}^{3+}$ and $\mathrm{Ce}^{4+}$, the oxygen vacancy was produced in the redox process, which was benefit for the photocatalysis $[8,10]$.

For the $\mathrm{O} 1 \mathrm{~s}$ spectrum of Figure 6 (c), the low binding energy phase $(\mathrm{E}(\mathrm{O} 1 \mathrm{~s})=530 \mathrm{eV})$ can be attributed to the lattice oxygen $\left(\mathrm{O}_{1}\right)$, while the high binding energy phase $(\mathrm{E}(\mathrm{O} 1 \mathrm{~s})=532 \mathrm{eV})$ could be attributed to the surface chemical adsorption of oxygen (Os), such as surface hydroxyl $(-\mathrm{OH}) . \mathrm{O}_{\mathrm{s}} /\left(\mathrm{O}_{\mathrm{s}}+\mathrm{O}_{\mathrm{l}}\right)$ can be used as active centers for catalytic reactions $[6,13]$.
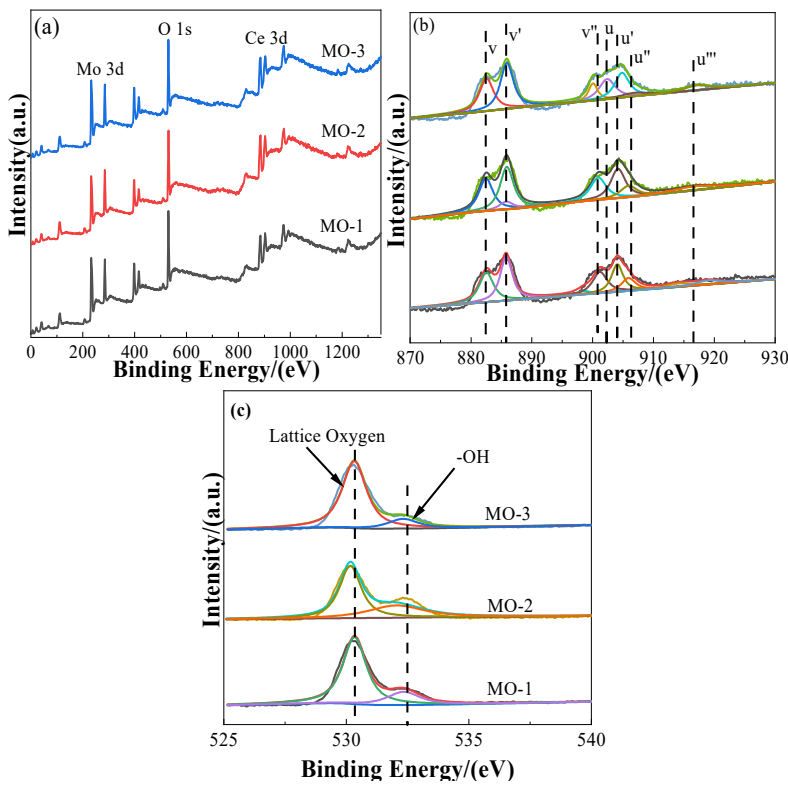

Figure 6 XPS spectra of Ce/Mo metal oxides with different $\mathrm{Ce} / \mathrm{Mo}$ molar ratios

(a) survey spectrum; (b) Ce 3d; (c) $\mathrm{O} 1 \mathrm{~s}$

The ratios of different valence elements in $\mathrm{Ce} / \mathrm{Mo}$ metal oxides were listed in the Table 1 . The redox equilibrium reaction between $\mathrm{Ce}^{4+}$ and $\mathrm{Ce}^{3+}$ promoted the electron transfer and exchange, which could result in the cause of oxygen vacancy [6]. Comparatively, MO-2 had a higher $\mathrm{O}_{\mathrm{s}} /\left(\mathrm{O}_{\mathrm{s}}+\mathrm{O}_{1}\right)$, which was beneficial to the photo-degradation performance.

Table 1 Proportion of different valence element in Ce/Mo metal oxides with different $\mathrm{Ce} / \mathrm{Mo}$ molar ratios

\begin{tabular}{|c|c|c|}
\hline \multirow{2}{*}{ Catalysts } & \multicolumn{2}{|c|}{ Proportion/\% } \\
\cline { 2 - 3 } & $\mathbf{C e}^{\mathbf{3}} /\left(\mathbf{C e}^{\mathbf{3 +}}+\mathbf{C e}^{\mathbf{4 +}}\right)$ & $\left.\mathbf{O}_{\mathbf{s}} / \mathbf{( O}_{\mathbf{s}}+\mathbf{O}_{\mathbf{~}}\right)$ \\
\hline MO-1 & 42.71 & 21.57 \\
\hline MO-2 & 43.53 & 37.44 \\
\hline MO-3 & 45.39 & 15.43 \\
\hline
\end{tabular}




\subsection{Photocatalytic performance}

The photocatalytic performance of Ce/Mo molar ratios on the photocatalytic performance were shown in Figure 7. MO-2 exhibited the optimum photocatalytic performance, with $80 \%$ degradation rate of $50 \mathrm{mg} / \mathrm{L}$ methyl orange solution at $18 \mathrm{~min}$. As shown in Table 2, the absorption rate of MO-1 was excellent due to its high surface area, while the photocatalytic performance of MO-2 was the best due to its regular structure as well as the high surface chemical adsorption of oxygen.

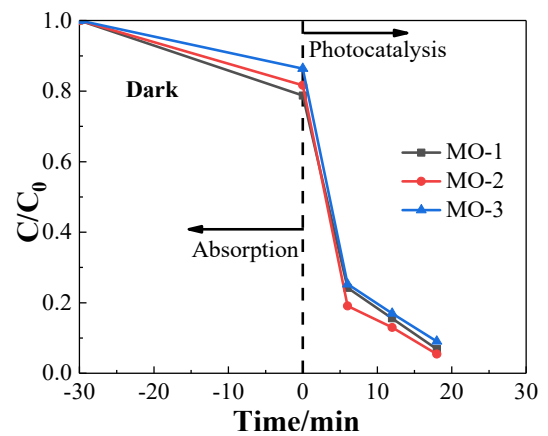

Figure 7 Effect of Ce/Mo molar ratios on the photocatalytic performance

Table 2 Adsorption and degradation rate of Ce/Mo metal oxides with different $\mathrm{Ce} / \mathrm{Mo}$ molar ratios

\begin{tabular}{|c|c|c|}
\hline Simples & $\begin{array}{c}\text { Absorption rate/ } \\
\left(\mathbf{m g} \cdot \mathbf{L}^{-\mathbf{1}} \cdot \mathbf{m i n}^{-\mathbf{1}}\right)\end{array}$ & $\begin{array}{c}\text { degradation rate/ } \\
\left(\mathbf{m g} \cdot \mathbf{L}^{-\mathbf{1}} \cdot \mathbf{m i n}^{-\mathbf{1}} \mathbf{)}\right.\end{array}$ \\
\hline $\mathrm{MO}-1$ & 0.04 & 0.18 \\
\hline $\mathrm{MO}-2$ & 0.03 & 0.25 \\
\hline $\mathrm{MO}-3$ & 0.02 & 0.21 \\
\hline
\end{tabular}

\section{CONCLUSIONS}

Ce/Mo metal oxides were successfully prepared via DBD plasma and showed excellent photocatalytic performance. The degradation rate of $1000 \mathrm{~mL}(50 \mathrm{mg} / \mathrm{L})$ methyl orange could reach up to $80 \%$ within $18 \mathrm{~min}$. Characterization analysis showed that Ce/Mo metal oxides with Ce/Mo molar ratio of 4:1 exhibited more surface chemical adsorption of oxygen, which was very beneficial to photocatalytic performance. DBD plasma could provide a novel method for the preparation of efficient photocatalysts.

\section{ACKNOWLEDGEMENTS}

This project was supported by Natural Science Foundation of Shandong Province [ZR2020MB034] and the Talent Fund of Shandong Collaborative Innovation Center of Eco-Chemical Engineering from Qingdao University of Science and Technology [XTCXQN23].

\section{REFERENCES}

1. Chen, Q., Wang, H., Luan, Q. (2020) Synergetic effects of defects and acid sites of $2 \mathrm{D}-\mathrm{ZnO}$ photocatalysts on the photocatalytic performance. J. Hazard Mater., 385: 121527.
2. Sa-Nguanprang, S., Phuruangrat, A., Thongtem, T. (2019) Visible-light-driven photocatalysis of Gddoped $\mathrm{ZnO}$ nanoparticles prepared by tartaric acid precipitation method. J. Russ. J. Inorg. Chem., 64: $1600-1608$

3. Mardare, D., Mita, C., Cornei, N. (2016) Platinum role in hydrophilicity enhancement of $\mathrm{Cr}$-doped $\mathrm{TiO}_{2}$ thin films. J. Philos. Mag., 28: 1-16.

4. Liu, R., Zhao, D., Duan, L. (2020) Optical and photocatalytic properties of $\mathrm{Zn}_{1-x} \mathrm{Cd}_{x} \mathrm{O}$ nanoparticles with tuned oxygen vacancy. J. Alloys. Compd., 825: 153377.

5. Yuan, B., Zhang, B., Wang Z. (2017) Photocatalytic aerobic oxidation of toluene and its derivatives to aldehydes on $\mathrm{Pd} / \mathrm{Bi}_{2} \mathrm{WO}_{6}$. J. Chinese J. Catal., 38: 440-446.

6. Jaiswal, R., Bharambe, J., Patel, N. (2015) Copper and nitrogen co-doped $\mathrm{TiO}_{2}$ photocatalyst with enhanced optical absorption and catalytic activity. J. Appl. Catal. B: Environ., 168-169: 333-341.

7. Geng, Y., Chen, X., Yang, S. (2017) Promotional effects of $\mathrm{Ti}$ on a $\mathrm{CeO}_{2}-\mathrm{MoO}_{3}$ catalyst for the selective catalytic reduction of $\mathrm{NO}_{x}$ with $\mathrm{NH}_{3}$. J. ACS Appl. Mater. Inter., 9: 16951-16958.

8. Yasakau, K. A., Tedim, J., Zheludkevich, M. L. (2012) Cerium molybdate nanowires for active corrosion protection of aluminium alloys. J. Corros. Sci., 58: 41-51.

9. Yang, Z., Qi, W., Su, R. (2017) 3D flower-like micro/nano Ce-Mo composite oxides as effective bifunctional catalysts for one-pot conversion of fructose to 2,5-diformylfuran. J. ACS Sustain. Chem Eng., 5: 4179-4187.

10. Dargahi, M., Masteri-Farahani, M., Shahsavarifar, S. (2020) Microemulsion-mediated preparation of $\mathrm{Ce}_{2}\left(\mathrm{MoO}_{4}\right)_{3}$ nanoparticles for photocatalytic degradation of crystal violet in aqueous solution Environ. J. Sci. Pollut. R., 27: 12047-12054.

11. Wang, Z., Zhang, Y., Neyts, E.C. (2018) Catalyst preparation with plasmas: How does it work? J. ACS Catal., 8: 2093-2110.

12. Snoeckx, R., Bogaerts, A. (2017) Plasma technology-a novel solution for $\mathrm{CO}_{2}$ conversion? J. Chem. Soc. Rev., 46: 5805-5863.

13. Rouwenhorst, K., Yannick, E., Veer, K. (2020) Plasma-driven catalysis: green ammonia synthesis with intermittent electricity. J. Green Chem., 22: 6258-6287.

14. Mehta, P., Barboun, P. M., Engelmann, Y. (2020) Plasma-catalytic ammonia synthesis beyond the equilibrium limit. J. ACS Catal., 12: 6726-6734.

15. Navascues P, Perez J M O, Cotrino J. (2020) Unraveling discharge and surface mechanisms in plasma-assisted ammonia reactions. J. ACS Sustain. Chem. Eng., 8: 14855-14866.

16. Li, G., Wang, B., Liu, Y. (2008) Fabrication of superhydrophobic $\mathrm{ZnO} / \mathrm{Zn}$ surface with nanowires and nanobelts structures using novel plasma assisted 
thermal vapor deposition. J. Appl. Surf. Sci., 255: 3112-3116.

17. Liu, G., Li, Y., Chu, W. (2008) Plasma-assisted preparation of $\mathrm{Ni} / \mathrm{SiO}_{2}$ catalyst using atmospheric high frequency cold plasma jet. J. Catal. Commun., 9: 1087-1091.

18. Tao, X., Yang, C., Huang. L. (2019) Novel plasma assisted preparation of $\mathrm{ZnCuFeCr}$-layered double hydroxides with improved photocatalytic performance of methyl orange degradation. J. App. Surf. Sci., 507: 145053.

19. Khaledian, H. R., Zolfaghari, P., Kheyrollahi, P., (2020) Surface modification of $\mathrm{LaMnO}_{3}$ perovskite supported on $\mathrm{CeO}_{2}$ using argon plasma for highperformance reduction of NO. J. Environ. Chem. Eng., 9: 104581.

20. Ananth, A., Mok, Y. S. (2016) Dielectric barrier discharge (DBD) plasma assisted synthesis of $\mathrm{Ag}_{2} \mathrm{O}$ nanomaterials and $\mathrm{Ag}_{2} \mathrm{O} / \mathrm{RuO}_{2}$ nanocomposites. J. Nanomaterials, 6: 42.

21. Singh, G., Kushwaha, A., Sharma, M. (2020) Intriguing peroxidase-mimic for $\mathrm{H}_{2} \mathrm{O}_{2}$ and glucose sensing: a synergistic $\mathrm{Ce}_{2}\left(\mathrm{MoO}_{4}\right)_{3} / \mathrm{rGO}$ nanocomposites. J. Alloys. Compd., 825: 154134.

22. Kartsonakis, A., Kordas, G. (2010) Synthesis and characterization of cerium molybdate nanocontainers and their inhibitor complexes. J. Am. Ceram. Soc., 93: 65-73.

23. Dong, M.Y., Lin, Q., Sun, H. M. (2011) Synthesis of cerium molybdate hierarchical architectures and their novel photocatalytic and adsorption performances. Cryst. J. Growth Des., 11: 5002-5009.

24. X. Li, Y. Li. (2014) Selective catalytic reduction of $\mathrm{NO}$ with $\mathrm{NH}_{3}$ over Ce-Mo-O ${ }_{x}$ catalyst. J. Catal. Lett., 144: $165-171$.

25. Jiang, Y., Zhang, X., Lu, M. (2018) Activity and characterization of Ce-Mo-Ti mixed oxide catalysts prepared by a homogeneous precipitation method for selective catalytic reduction of $\mathrm{NO}$ with $\mathrm{NH}_{3}$. J. Taiwan Inst. Chem. E., 86: 133-140. 